\title{
Efikasi Diri, Kestabilan Emosi dan Keberhasilan Akademik Mahasiswa dalam Perkuliahan
}

\author{
Lina Arifah Fitriyah, Andri Wahyu Wijayadi, Nur Hayati \\ Universitas Hasyim Asy'ari \\ linaarifahfitriyah@gmail.com
}

\section{Sejarah Artikel}

diterima 8/01/2020

disetujui 27/2/2020

diterbitkan 1/08/2020

\begin{abstract}
This study aims to determine the relationship between self, stability of the transition to academic success. This research method uses the analysis method. Instruments in the study include selfefficacy questionnaire, transition stability questionnaire and the value of student learning outcomes during lectures for one semester (academic achievement). The results showed (1) there was an effect of self-efficacy on academic success of $7.6 \%$ while $92.4 \%$ was determined by other factors, and (2) there was an effect of stability of movement on academic achievement of $19.9 \%$ while $80.1 \%$ was determined by other factors. Thus there is a relationship between self-efficacy and the stability of the transition with student academic achievement. This explains the high self-efficacy and stability of students, academic success can also be high. Overcoming, Self-Efficacy and Stability of Student Logic is low then it could be that the Academic Student Advocacy Achievement is also low.

Keywords: Self-Efficacy, Emotional Stability, Student Academic Success
\end{abstract}

\begin{abstract}
Abstrak
Penelitian ini bertujuan untuk mengetahui hubungan efikasi diri, kestabilan emosi terhadap keberhasilan akademik. Metode penelitian ini menggunakan analisis korelasi. Instrumen dalam penelitian antara lain angket efikasi diri, angket kestabilan emosi dan nilai hasil belajar mahasiswa selama menempuh perkuliahan selama satu semester (keberhasilan akademik). Hasil penelitian menunjukkan bahwa (1) ada pengaruh efikasi diri terhadap keberhasilan akademik sebesar 7,6\% sedangkan $92,4 \%$ ditentukan oleh faktor lain, dan (2) ada pengaruh kestabilan emosi terhadap keberhasilan akademik sebesar 19,9\% sedangkan 80,1\% ditentukan oleh faktor lain. Dengan demikian ada hubungan efikasi diri dan kestabilan emosi dengan keberhasilan akademik mahasiswa. Hal ini menerangkan bahwa efikasi diri dan kestabilan emosi mahasiswa yang tinggi, keberhasilan akademiknya pun bisa tinggi pula. Sebaliknya, efikasi diri dan kestabilan emosi mahasiswa rendah maka bisa jadi capaian keberhasilan akademik mahasiswa pun rendah pula.

Kata Kunci: Efikasi Diri, Kestabilan Emosi, Keberhasilan Akademik Mahasiswa
\end{abstract}




\section{PENDAHULUAN}

Berhasil, sukses dan berprestasi secara akademik merupakan dambaan dan keinginan bagi mahasiswa. Keberhasilan akademik dipandang sebagai cerminan kualitas mahasiswa dalam kemampuan intelektual, ketekunan, dan menyesuaikan diri. Keberhasilan akademik dapat dilihat dari hasil penilaian yang diperoleh mahasiswa mengenai pengetahuan, sikap dan keterampilan yang dinyatakan dalam bentuk nilai. Penilaian tersebut biasanya diperoleh dari nilai UTS, UAS dan tugas-tugas yang relevan dalam perkuliahan yang mereka tempuh.

Namun untuk mencapai berhasil secara akademik tidak semua mahasiswa dapat memaksimalkan potensi yang dimilikinya karena untuk mencapai berhasil, sukses dan berprestasi secara akademik dipengaruhi oleh beberapa faktor. Faktor tersebut diantaranya faktor eksternal dan internal. Faktor eksternal adalah faktor yang berasal dari lingkungan sedangkan faktor internal berasal dari dalam diri mahasiswa itu sendiri termasuk di dalamnya efikasi diri dan kestabilan emosi (Sukmawati dkk, 2013).

Efikasi diri dan kestabilan emosi sebagai kondisi psikologis sangat penting bagi mahasiswa dalam mencapai keberhasilan dan memperoleh pengalaman belajarnya (Fitriyah, 2019). Efikasi diri yang tinggi dan emosi yang stabil perlu ditanamkan dalam diri mahasiswa sehingga mereka dapat mencapai keberhasilan akademik yang tinggi. Namun hal tersebut masih sulit untuk dilakukan. Masih banyak mahasiswa yang memiliki masalah terhadap keyakinan pada dirinya. Mahasiswa terkadang menganggap 'enteng' suatu matakuliah misalnya Bahasa Indonesia. Sebagian mahasiswa beranggapan bahwa matakuliah tersebut mudah dipelajari dan dipahami karena bahasa yang digunakan dalam berkomunikasi sehari-hari, namun keberhasilan akademik yang diperoleh terkadang kurang (Sukmawati dkk, 2013)..

Berdasarkan kenyataan tersebut maka dilakukan wawancara dengan beberapa mahasiswa angkatan 2015 dan diperoleh hasil bahwa ada perbedaan saat menjadi siswa dan mahasiswa. Tugas-tugas matakuliah dari dosen ada tenggang waktu pengumpulan sehingga mahasiswa biasanya akan mengulur-ulur waktu dalam pengerjaannya. Mereka akan mengumpulkan tugas tersebut satu hari sebelum deadline karena anggapan mahasiswa itu hal yang wajar dan mahasiswa yang lain juga melakukan tersebut.

Masih banyak pula mahasiswa yang belajarnya sistem kebut semalam dengan alasan banyak kegiatan yang mereka lakukan di dalam maupun di luar kampus sehinga hasil yang mereka peroleh tidak maksimal. Mahasiswa dituntut untuk segera menyelesaikan tugastugas akademik sehingga menyebabkan mahasiswa mengalami keadaan jenuh dan tertekan pada saat perkuliahan. Mahasiswa berpendapat bahwa setiap matakuliah akan selalu ada tugas-tugas akademik yang sangat menguras pikiran dan tenaga sehingga mereka susah membagi waktu antara mengerjakan tugas kuliah, mengerjakan laporan, kuis, ujian tengah semester, ujian akhir semester dan dosen yang sulit ditemui. Jika hal tersebut terus 
berlanjut, maka akan mempengaruhi keberhasilan akademik mahasiswa.

Berdasarkan paparan masalah diatas, maka perlu dilaksanakan penelitian empiris. Hal inilah yang mendorong peneliti untuk mengadakan penelitian mengenai hubungan efikasi diri dan kestabilan emosi terhadap keberhasilan akademik mahasiswa dalam perkuliahan agar diketahui secara jelas hubungan ketiganya.

\section{METODE}

Penelitian ini dirancang sebagai penelitian korelasional untuk mengetahui ada atau tidak hubungan antara efikasi diri, kestabilan emosional, dengan keberhasilan akademik. Anisa (2010), penelitian korelasi yaitu penelitian untuk mengetahui hubungan antara dua variabel atau lebih tanpa ada upaya untuk mempengaruhi variabel tersebut. Variabel penelitian ini terdiri dari variabel bebas yaitu efikasi diri dan kestabilan emosional dan variabel terikat yaitu keberhasilan akademik.

Sampel yang dipakai dalam penelitian ini adalah mahasiswa Prodi Pendidikan IPA Unhasy angkatan 2015. Jumlah sampel pada penelitian ini adalah 19 mahasiswa.

Instrumen dalam penelitian antara lain angket efikasi diri, angket kestabilan emosi dan nilai hasil belajar mahasiswa selama menempuh perkuliahan selama satu semester (keberhasilan akademik).

Adapun aspek angket efikasi diri terdiri dari (1) magnitude, (2) generality, dan (3) strength. Aspek angket kestabilan meliputi intrapersonal, (2) interpersonal, (3) orientasi kognitif, (4) afeksi, ada tiga item pernyataan dalam angket.

Teknik analisis data yang dilakukan adalah (1) pemberian skor pada hasil angket, (2) menghitung nilai mean dan standar deviasi agar bisa diketahui kategori efikasi diri, kestabilan emosional terhadap keberhasilan akademik mahasiswa, dan (3) uji statistik penelitian yaitu uji normalitas, uji linearitas, dan uji $\mathrm{t}$ dengan tingkat signifikansi 5\% menggunakan program Statistical Package for Social Sciences (SPSS) versi 16.0 for windows.

Kategori tingkat efikasi diri, kestabilan emosi dan keberhasilan akademik dilakukan dengan menghitung batasan kriteria yang mengacu berdasarkan Azwar (2009) sebagai berikut:

a. Tinggi $=$ Mean $+1(S D) \leq X$

b. Sedang = Mean $-1(\mathrm{SD}) \leq \mathrm{X}<$ Mean +1 (SD)

c. Rendah $=\mathrm{X}<$ Mean -1 (SD)

\section{PEMBAHASAN}

Efikasi diri dan kestabilan emosi mahasiswa diketahui melalui hasil angket yang dikerjakan sejujurnya oleh mahasiswa. Data hasil efikasi diri, kestabilan emosi, dan keberhasilan akademik dapat dideskripsikan pada Tabel 1 berikut ini: 
Tabel 1 Deskripsi Data Efikasi Diri, Kestabilan Emosi, dan Keberhasilan Akademik

\begin{tabular}{cccc}
\hline & Efikasi Diri & $\begin{array}{c}\text { Kestabilan } \\
\text { Emosi }\end{array}$ & $\begin{array}{c}\text { Keberhasilan } \\
\text { Akademik }\end{array}$ \\
\hline Mean & 39.3684 & 76.5263 & 63.4737 \\
\hline Standar Deviasi & 4.57299 & 6.30140 & 7.28292 \\
\hline
\end{tabular}

Berdasarkan Tabel 1 di atas, maka dapat dilihat nilai mean (M) dan standar deviasi (SD) tiap variabel sebagai berikut:

\section{Variabel Efikasi Diri}

Nilai mean (M) sebesar 39,37 dengan standar deviasi (SD) sebesar 4,57. Kategori tingkat efikasi diri disajikan pada Tabel 2 dibawah ini:

Tabel 2. Kategorisasi Efikasi Diri Mahasiswa

\begin{tabular}{|c|l|c|c|c|}
\hline No & \multicolumn{1}{|c|}{ Skor } & Kategori & Frekuensi & Persentase (\%) \\
\hline 1 & $\mathrm{X} \geq 44$ & Tinggi & 4 & 21,05 \\
\hline 2 & $35<\mathrm{X}<44$ & Sedang & 12 & 63,16 \\
\hline 3 & $\mathrm{X}<35$ & Rendah & 3 & 15,79 \\
\hline \multicolumn{3}{|c|}{ Jumlah } & 19 & 100 \\
\hline
\end{tabular}

Berdasarkan hasil Tabel 2 diatas, diketahui bahwa mahasiswa Pendidikan IPA angkatan 2015 Universitas Hasyim Asy'ari termasuk dalam golongan efikasi diri sedang yaitu 12 mahasiswa $(63,16 \%)$. Ini disebabkan mahasiswa lebih cenderung memiliki kepercayaan dalam dirinya yang tidak bisa memusatkan perhatian sehingga Variabel Kestabilan Emosi

Nilai mean (M) sebesar 76,53 dengan standar deviasi (SD) sebesar 6,30. Kategori tingkat kestabilan emosi disajikan pada Tabel 3 dibawah ini:

Tabel 3. Kategorisasi Kestabilan Emosi Mahasiswa Angkatan 2015

\begin{tabular}{|c|l|c|c|c|}
\hline No & \multicolumn{1}{|c|}{ Skor } & Kategori & Frekuensi & Persentase (\%) \\
\hline 1 & $\mathrm{X} \geq 83$ & Tinggi & 3 & 15,79 \\
\hline 2 & $70<\mathrm{X}<83$ & Sedang & 14 & 73,68 \\
\hline 3 & $\mathrm{X}<73$ & Rendah & 2 & 10,53 \\
\hline \multicolumn{3}{|c|}{ Jumlah } & 19 & 100 \\
\hline
\end{tabular}

Pada Tabel 3, bisa dilihat bahwa mahasiswa sebagian besar tergolong kestabilan emosi yang sedang sebanyak 14 mahasiswa (73,68\%). Hal ini berarti mahasiswa tersebut cenderung baik dalam mengendalikan mereka lebih labil dalam memastikan kepercayaan dirinya dalam menghadapi suatu hal. Ahmad \& Safaria (2013) menyatakan selfefficacy made person believe with their capability to overcome obstacle that hindering achievement their goal. They believe that they can reach their willingness, their dreams, and their goal in effective ways. emosinya sehingga mahasiswa tersebut mampu membawa suasana hati tenang dengan kondisi yang terjadi di sekelilingnya, sanggup menyepadankan diri, tidak lekas gelisah dan juga tidak lekas marah. 
Serebryakova, etc. (2016) menyatakan emotional stability is one of the main individual and psychological characteristics that determines the personality's stability to stress-producing effects of difficult life situations. It is emotional stability that has a leading role when it Tabel 4 berikut ini: comes to achieving good results in educational, sport and professional fields.

Untuk mengetahui besarnya pengaruh efikasi diri dan kestabilan emosi terhadap keberhasilan akademik dapat dilihat dari nilai $R$ determinan pada

Tabel 4. Nilai R Efikasi Diri dan Kestabilan Emosi Terhadap Keberhasilan Akademik

\begin{tabular}{ccc}
\hline & Efikasi Diri & Kestabilan Emosi \\
\hline $\mathrm{R}$ & .076 & .199 \\
\hline $\mathrm{R}$ Square & .006 & .040 \\
\hline Adjusted R Square & -.053 & -.017 \\
\hline Std. Error of The Estimate & 7.473 & 7.344 \\
\hline
\end{tabular}

Besarnya $R$ determinan pada keberhasilan akademik mahasiswa efikasi diri adalah 0,076, selain efikasi diri dan kestabilan menerangkan ada pengaruh variabel emosi. Ada faktor internal dan bebas terhadap variabel terikat yaitu eksternal yang bisa mempengaruhi $7,6 \%$. Jadi pengaruh efikasi diri terhadap keberhasilan akademik 7,6\% sedangkan 92,4\% ditentukan oleh faktor lain. Sedangkan besarnya $R$ determinan pada kestabilan emosi adalah 0,199, menerangkan ada pengaruh variabel bebas terhadap variabel terikat adalah 19,9\%. Jadi pengaruh kestabilan emosi terhadap keberhasilan akademik sebesar $19,9 \%$ sedangkan $80,1 \%$ ditentukan oleh faktor lain.

Berdasarkan Tabel 4 keberhasilan akademik mahasiswa. Muhibbin Syah (2010) memaparkan bahwa faktor internal yang mempengaruhi belajar peserta didik adalah (1) aspek fisiologis (yang bersifat jasmani) meliputi tonus (ketegangan otot), keadaan mata dan telinga, (2) aspek psikologis (yang bersifat rohani) meliputi sikap, intelegensi, motivasi, bakat, dan minat. Sedangkan faktor eksternal meliputi lingkungan sosial (keluarga, masyarakat, teman, guru dan staf dan bahwasanya ada banyak faktor-faktor lingkungan non sosial (alam, sekolah, lain yang turut mempengaruhi rumah, peralatan, dan sebagainya). Uji Hipotesis

Uji hipotesis yang digunakan adalah uji korelasional untuk menentukan ada hubungan antara efikasi diri dan kestabilan emosi dengan keberhasilan akademik mahasiswa dengan taraf signifikansi 0,05 atau dengan taraf kepercayaan 95\%. Hasil uji korelasinya dapat dilihat pada Tabel 5 di bawah ini:

Tabel 5. Hasil Uji Korelasi Efikasi Diri dan Kestabilan Emosi terhadap Keberhasilan Akademik

\begin{tabular}{ccc}
\hline Verifikasi & $\mathbf{t}$ & Sig. (2-tailed) \\
\hline Efikasi Diri & 37.525 & .000 \\
\hline Kestabilan Emosi & 52.936 & .000 \\
\hline Keberhasilan Akademik & 37.990 & .000 \\
\hline
\end{tabular}


Dari Tabel 5 diatas diperoleh keberhasilan akademik mahasiswa

hubungan secara signifikan. Efikasi diri sangat relevan dengan pembelajaran. Schunk (2012) memaparkan bahwa efikasi diri mengacu pada keyakinan dan kemampuan yang dilakukan seseorang untuk belajar dan melakukan tindakan. Seseorang yang memiliki keyakinan efikasi diri yang tinggi akan cenderung menghasilkan usaha lebih banyak ketika menghadapi kesulitan-kesulitan dan bertahan dalam suatu tugas ketika orang tersebut memiliki keterampilan yang diperlukan dalam menyelesaikan tugasnya. Efikasi diri adalah perasaan seseorang dalam keadaan sadar tentang dirinya. Seseorang yang memiliki keyakinan, kemampuan dan usaha yang baik dan maksimal dalam mecapai suatu misi/target maka ia pun akan termotivasi untuk melakukan tugasnya dengan baik.

Seseorang yang mempunyai efikasi diri akan bisa memanajemen dirinya sendiri termasuk memotivasi dirinya sendiri sehingga ia mampu menyelesaikan berbagai tugas akademik dengan baik tanpa perlu menunda-nunda waktu. Sebaliknya jika seseorang kurang memiliki efikasi diri maka ia pun akan merasa kurang mampu untuk menyelesaikan berbagai tugas akademik sehingga ia tidak percaya diri dan selalu pesimis dalam mengerjakan tugas kuliah.

Jika seseorang merasa suatu keadaan berhasil atau memperhatikan seseorang sukses, berada dalam suasana hati yang baik, tidak gelisah ketika bertemu muka dengan suatu tugas maka akan menaikkan keperayaan bahwa ia sanggup untuk sukses dalam menyelesaikan tugas tersebut (generality) dengan tingkat kesukaran tertentu (magnitude), signifikansi antara efikasi diri dengan $0,000<0,05$ yang artinya terdapat sehingga ia makin kukuh (strength) dalam menghadapi perilaku dan kesanggupannya untuk tetap fokus dan tekun sampai berhasil. Indikasi seperti inilah seseorang dikatakan memiliki efikasi diri bahkan sebaliknya efikasi diri tidak tinggi akan menjauhkan diri dari semua tugas dan pasrah ketika timbul masalah. Hal ini dipertegas oleh Fitriyah (2019) dalam bukunya bahwasanya diperlukan penanaman perilaku dengan mengurangi atau menghilangkan dalam menunda dalam mengerjakan tugas dan menyelesaikan masalah agar terbentuk efikasi diri.

Berdasarkan Tabel 5 diatas, signifikansi antara kestabilan emosi dengan keberhasilan akademik mahasiswa adalah $0,000<0,05$ yang artinya terdapat hubungan kestabilan emosi keberhasilan. Kestabilan emosi merupakan salah satu ciri kematangan emosional dengan kondisi yang stabil. Karakteristik emosi yang stabil yaitu tidak ada perubahan perasaan secara singkat dan tak teratur, mempunyai rasa keyakinan diri, realistis, serta optimis, tidak kepikiran dengan rasa cemas, kesepian dan perasaan bersalah (Chusnul Chotimah, 2010).

Emosi seseorang akan memiliki kematangan yang ditandai dengan kemampuan individu untuk merespon emosi yang tepat dengan kondisi tertentu pada situasi yang tidak menyenangkan. Kematangan emosi biasanya individu bisa mengontrol emosinya sesuai dengan lingkungan sekitar dan cita-cita dalam kehidupannya.

Jika kestabilan emosi seseorang makin tinggi maka ia cenderung ia memperoleh hasil belajar yang lebih baik. Sebaliknya semakin tidak stabil 
emosi mahasiwa, maka ia semakin rendah kecenderungannya untuk memperoleh hasil belajar yang lebih baik. Mahasiswa yang berkondisi emosinya stabil (sehat secara emosional) maka ia mampu mengendalikan emosi, tidak mudah cemas dan khawatir, lebih percaya diri serta mudah konsentrasi sehingga segala aktivitas yang dilakukan pun akan semakin lancar.

Fitriyah (2019) mengemukakan bahwasanya untuk mengatur emosional dengan sengaja harus dilakukan melalui menenangkan diri, dan mengendalikan perasaan. Dengan demikian kestabilan emosi bisa dikelola dengan bersabar dalam menghadapi masalah.

\section{SIMPULAN}

Berdasarkan penelitian tentang efikasi diri, kestabilan emosi dan keberhasilan akademik mahasiswa dalam perkuliahan dapat disimpulkan bahwa mahasiswa Pendidikan IPA Unhasy memiliki kategori efikasi diri sedang $(63,16 \%)$, kestabilan emosi sedang $(73,68 \%)$, dan keberhasilan akademik sedang $(63,16 \%)$. Hal ini menunjukkan bahwa (1) ada pengaruh efikasi diri terhadap keberhasilan akademik sebesar $7,6 \%$ sedangkan $92,4 \%$ ditentukan oleh faktor lain, dan (2) ada pengaruh kestabilan emosi terhadap keberhasilan akademik sebesar $19,9 \%$ sedangkan $80,1 \%$ ditentukan oleh faktor lain. Dengan demikian ada hubungan efikasi diri dan kestabilan emosi dengan keberhasilan akademik mahasiswa. Hal ini menerangkan bahwa efikasi diri dan kestabilan emosi mahasiswa yang tinggi, keberhasilan akademiknya pun bisa tinggi pula. Sebaliknya, efikasi diri dan kestabilan emosi mahasiswa rendah maka bisa jadi capaian keberhasilan akademik mahasiswa pun rendah pula.
Hasil penelitian ini bisa menjadi sumber informasi akan pentingnya efikasi diri dan kestabilan emosi dalam mencapai keberhasilan akademik mahasiswa. Mahasiswa diharapkan dapat mengenali kemampuan dan kekurangan dirinya dalam mengerjakan tugas untuk mencapai kegiatan belajar dalam bidang akademik dalam menetapkan keberhasilan yang hendak dicapai sehingga bisa mengelola dirinya dengan baik dan lebih antisipasi terhadap kemungkinan hambatan dan kesulitan yang akan dihadapinya untuk meraih kesuksesan belajar di perguruan tinggi.

Ada banyak faktor yang dapat mempengaruhi keberhasilan akademik mahasiswa yang kurang dikontrol dalam penelitian seperti intelegensi, bakat, minat, motivasi, kesehatan, pendekatan belajar, faktor internal (dosen, fasilitas belajar di kampus). Diharapkan peneliti selanjutnya bisa mengontrol faktorfaktor tersebut.

\section{DAFTAR PUSTAKA}

Ahmad, Alay \& Safaria, Triantoro. 2013. Effects of Self-Efficacy on Students' Academic Performance. Journal of
Educational, Health and Community Psychology, Vol. 2 No. 1. 
Annisa, W. 2010. Metode Penelitian Korelasional.

Http://bintangkecilungu.wordpres s.com/2010/10/31/metodepenelitian-korelasional-2/.

Azwar, Saiffudin. 1999. Penyusunan Skala Psikologi. Yogyakarta: Pustaka Belajar.

Chusnul Chotimah. 2010. Hubungan Kestabilan Emosi Dengan Prestasi Belajar Pada Siswa Kelas $X$ SMA Negeri 1 Karanganom Klaten. Skripsi. Fakultas Kedokteran Universitas Sebelas Maret.

Fitriyah, Lina Arifah; etc. 2019. Menanamkan Efikasi Diri dan Kestabilan Emosi. Jombang: LPPM Unhasy Tebuireng Jombang.

Permendikbud. 2013 SNPT. Kementrian Pendidikan dan Kebudayaan Direktorat Jenderal Pendidikan Tinggi dan dan Bandar Standar Nasional Pendidikan.

Serebryakova, Tat'yana A.; Morozova, Lyudmila B.; Kochneva, Elena M.; Zharova, Darya V., Kostyleva, Elena A. and Kolarkova, Oxana G. 2016. Emotional Stability as a Condition of Students' Adaptation to Studying in a Higher Educational Institution. International Journal Of Environmental \& Science Education, Vol. 11, NO. 15, 7486-74

Sugiyono. 2007. Metode Penelitian Kuantitatif Kualitatif dan $R \& D$. bandung: Alfabeta.

Sukmawati, N.P.F., Suarni, N.K., \& Renda, N.T. 2013. Hubungan antara Efikasi Diri dan Kebiasaan Belajar terhadap Prestasi Belajar Siswa Kelas V SDN di Kelurahan Kaliuntu
Singaraja. Mimbar PGSD Undiksha, 1(1).

Schunk, D.H. 2012. Learning Theories An Educational Perspective. Boston: Publishing As Allyn \& Bacon 501.

Syah, Muhibbin. 2010. Psikologi Pendidikan. Bandung: Remaja Rosda Karya.

UU RI Nomor 12 Tahun 2012 tentang Pendidikan Tinggi. (Online), pdf. 